\title{
The Effect of Humor-Integrated Pictures Using Quizlet on Vocabulary Learning of EFL Learners
}

\author{
Mehdi Solhi Andarab ${ }^{1, *}$ \\ ${ }^{1}$ School of Education, Istanbul Medipol University, Istanbul, Turkey \\ *Correspondence: School of Education, Istanbul Medipol University, Istanbul, Turkey. Tel: 90-216-681-5100. E-mail: \\ solhi.mehdi@gmail.com
}

Received: March 2, 2019

Accepted: March 18, 2019 Online Published: April 3, 2019

doi:10.5430/jct.v8n2p24

URL: https://doi.org/10.5430/jct.v8n2p24

\begin{abstract}
The recent improvements in technology and their integration in language learning have played a facilitating role in vocabulary acquisition. Quizlet, an online teacher-/student-friendly tool, is one of the leading applications in vocabulary acquisition. Along with the effectiveness of visualization in acquiring vocabulary, humor has been also extensively indicated to carry a significant role in language learning. With all its facilitating features, the integration of technology, humor, and vocabulary can be achieved via Quizlet. In this study, the visual integration of humor accompanying vocabulary on Quizlet was taken into scrutiny to see to what extent humor-integrated pictures on Quizlet account for the retention of vocabulary acquisition. With this purpose, this study examined the effect of humor-integrated pictures on vocabulary acquisition of 45 intermediate English as a foreign language (EFL) learners on Quizlet. In so doing, the experimental group received a series of unknown vocabulary items for which the integrated pictures were humorous, while the vocabulary items assigned for the control group were identical, but in non-humorous contexts. At the end, an independent samples t-test applied on the scores achieved from a posttest indicated a significant difference in scores of the control group and that of the experimental group. In fact, the learners in the experimental group significantly outperformed their counterparts in the control group. The results indicated that linking vocabulary items with humorous pictures is more effective than using non-humorous context in learning vocabulary. Apparently, as the results indicate, the significant effectiveness of technology in vocabulary learning can be boosted with the help of humorous context. The findings shed light on the importance of technology in language learning and its linking with humor in vocabulary learning.
\end{abstract}

Keywords: humor, humor-integrated pictures, Quizlet, vocabulary acquisition

\section{Introuction}

The recent improvements in technology and computer and their integration in language learning have played an undeniable and facilitating role in English language learning classrooms. The new generation is digital natives (Prensky, 2001) or the Net generation (Tapscott, 1998), and enjoy using the latest technology such as online resources, cell phones, and applications. Prensky $(2001$, p. 1) conceptualizes digital natives as a young generation of learners who have grown up engrossed in recent digital technological gadgets. The young generation is "surrounded by and using computers, videogames, digital music players, video cams, cell phones, and all the other toys and tools of the digital age". The advocates of digital native believe that educational communities must quickly respond to the technological needs of the new generation students (Frand, 2002; Howe \& Strauss, 2000). As far as language learning and particularly English considered, the linking of technology and language learning process seems to be a must so as to meet the needs of the generation students. This is due to the fact that digital natives are believed to learn differently in comparison to the past generations of students (Bennett, Maton, \& Kervin, 2008). The teaching approaches and the educational system that are currently being used in educational settings are criticized by Prensky (2001) and Tapscott (1998), believing that they are no longer in line with the expectations of the generation learners, and these approaches and systems do not fulfill the different motivational, social, and intellectual requirements of the current generation. 


\subsection{Technology and Vocabulary Acquisition}

Vocabulary learning possesses a pivotal role in the process of second or foreign language acquisition, and it is regarded as building blocks of a language (Francis \& Simpson, 2009; Moeller, Olha, \& Masmaliyeva, 2009; Nation, 2001). The growing body of literature is replete with studies assessing the most effective paths to acquire vocabulary (Hairrell, Rupley, \& Simmons, 2011; Liu \& Zhang, 2018; Nie \& Zhou, 2017; Yu \& Altunel, 2018). Recently, the growing utilization of different mobile gadgets such as iPad in education has offered a considerable learning opportunity for the language learners to build up their vocabulary knowledge in particular. Klopfer, Squire, and Jenkins (2002) underline five facilities that portable technology has provided: portability- the possibility to carry the mobile devices anywhere, social interactivity - the possibility to exchange information and collaborate using portable gadgets, context sensitivity - the possibility to obtain information unique to the location we are in, connectivity- the possibility to connect online to other devices, and individuality - the possibility to develop a unique and user-specific schedule, or program of learning or investigation. All the stated possibilities have paved the way for the both incidental and intentional vocabulary learning. While incidental vocabulary learning points to learning new vocabulary items from different contexts without obtaining explicit instruction (Schmidt, 1994), intentional vocabulary learning refers to any particular and deliberate steps taken to acquire new vocabulary items. Deng and Trainin (2015) emphasize that intentional vocabulary learning is a prerequisite for a higher chance of retention and mastery of vocabulary items. They add that the utilization of portable gadgets provides learners with authentic and rich context for incidental and intentional vocabulary learning. Appearantly, the accelerating advances in technology and vocabulary applications in particular possess a significant role in acquiring vocabulary and consequently increasing retention.

A myriad of studies have been conducted to investigate the integration of technology into learning vocabulary and its effects on the students' vocabulary learning (e.g., Basoglu \& Akdemir, 2010; Clark, 2013; Deng \& Trainin, 2015, Nation; 2001). Using vocabulary learning programs on cellphones, say, was reported to be more productive to build up students' vocabulary than using paper flashcards (Basoglu \& Akdemir, 2010). In a different study, Zhang, Song and Burston (2011) concluded that being frequently exposed to the vocabulary items in a short-term spaced manner, i.e., restudying the same vocabulary items, daily via cellphones are more helpful than conducting massed vocabulary learning on paper. Vocabulary learning through cellphones is also emphasized by Nation (2001), stating that it boosts the exposure to vocabulary items and motivates students to review vocabulary frequently. Clark (2013) examined the effectiveness of using Vocabulary Builder, a vocabulary application, on the vocabulary acquisition of elementary language learners. The application was reported to facilitate vocabulary acquisition as the learners had exposure to both visual and auditory facilities of the application. The participants also indicated a higher motivation and more level of learner engagement in acquiring words. In Wang et al.'s (2015) study, the learner engagement and motivation were similarly reported to be higher in the experimental group whose members utilized a vocabulary application named the Learn British English WordPower. They also outperformed their counterparts in the control group in terms of acquiring vocabulary. Rezaei, Mai, \& Pesaranghader (2014) also investigated the effect of multimedia courseware on vocabulary acquisition. Result indicated a positive change in the learners' performance, and the utilization of the applications was reported to help to improve vocabulary acquisition, class participation and confidence of the learners. In Taj et. al.'s (2017) study, the learners whose acquired vocabulary was with the help of technology exceled their counterparts for whom the technology was not integrated in the process of learning vocabulary.

\subsection{Humor and Language Learning}

Along with the importance of technology in learning vocabulary, the role of humor in language learning has been thoroughly taken into consideration in research. Berk (1998), for instance, underlines the psychological and physiological effects of humor on the language learners. He clarifies that classrooms where humor is integrated in the process of learning is likely to lower anxiety, relieve stress, develop self-esteem, and build up motivation. With regard to the physiological effects of humor, he points out that humor and laughter can maximize learning through promoted respiratory efficiency and blood circulation, lower pulse rate and blood pressure, lead to exercise of the chest muscles, increase oxygen levels in the blood, and eventually cause endorphins to be released into the bloodstream. Therefore, through reducing stress and learner anxiety in the classroom, humor would constitute an invaluable resource for promoting the classroom atmosphere (Huy Hoang \& Petraki, 2006). A great number of scholars (e.g., Askildson, 2005; Garner, 2003; Harmer, 2007; \& Oxford, 1999) in similar assert the importance of humor and how it can pave the way for enhancing learning and reduce anxiety, and argue in favor of a relaxing and psychologically secure, and supportive classroom atmosphere that is likely to reassure risk-taking, and enhance learners' motivation and self-confidence. Dornyei (2001) also advocates the integration of humor in the process of 
teaching and the establishment of an enjoyable classroom atmosphere, and considers them as motivational teaching strategies. Garner (2003) similarly maintains that the application of contextually appropriate humor has been indicated to improve the classroom environment and ease the process of language learning. In fact, it paves the way for us to perceive information or circumstances with a new perspective that might lead to novel insights. Importantly, both students and colleagues often value humor.

In parallel with the undeniably facilitating role of humor in learning, some other scholars argue in favor of comprehension or retention of information with the help of humor in the classroom (e.g., Blyth \& Ohyama, 2011; Desberg, Henschel, \& Marshall, 1981; Kaplan \& Pascoe, 1977). Mre than three decades ago, Kaplan \& Pascoe (1977) investigated the effect of humor and humorous examples upon the comprehension and retention of lecture material. Results indicated that the retention of humorous material was significantly improved by being exposed to a lecture with humorous examples illustrating concepts. In a different study, years ago, humorous lecture was reported to facilitate the retention of information significantly (Desberg, Henschel, \& Marshall, 1981). Pollack and Freda (1997, cited in Aria \& Tracey, 2003) also believe that integrating humor while presenting the materials in the classroom is most likely to help students avoid the inhibitions that they may bring to the classroom. In a study, Aria \& Tracey (2003) alike found that the students whose studied vocabulary lessons were humorous outperformed on achievement tests the ones whose lessons were non-humorous. Blyth \& Ohyama (2011) used a list of riddles telling activities in English language lessons at university with English language students to investigate vocabulary acquisition. The students' improved vocabulary knowledge with the help of humor is one of the findings reported in this study.

\subsection{Quizlet and Learning Vocabulary}

The integration of humor in technology to build up the vocabulary range of the learners, as aforementioned, has been emphasized in literature review, and it seems that the idea of integrating technology, humor, and vocabulary can be achieved via Quizlet. Quizlet is an excellent teacher-/student-friendly online application and a website providing seven powerful vocabulary learning tools for the creation of different vocabulary activities. Quizlet, as Shehane (2015) maintains, is an online vocabulary management system for teachers and students, and it helps them track vocabulary learning. Exceeding more than 150 million study sets to choose from, Quizlet is estimated to be the world's largest online learning community for student and teacher, and it is, undoubtedly, one of the most popular language learning technology tools on the internet. In order to create your own Quizlet, one needs to prepare a two-column list of words or phrases. This set of vocabulary can be a word and its definition, translation, synonym, antonyms, etc. After creating a two-column study set and importing it to the website, the site automatically and immediately creates the following seven game mode activities:

- Flashcards - Flashcards mode lets you study Quizlet sets as flashcards. One can play this activity to review the study set and listen to the pronunciation of the word or the phrase.

- Learn - Learn mode assesses how well you know the definitions of the words and helps keep track of what you miss. To move forward, one must type the answer and click on the Answer button or press Enter to see if the answer was correct or incorrect. So, this mode lets you focus on missed or unknown terms later in the study session.

- Spell - Spell mode lets you type what you hear to improve your spelling in this audio-powered study mode. This mode works well for studying a new language or practicing your spelling and pronunciation. There are 18 languages, enabling you to use Spell with a wide variety of sets.

- Test-Test randomly generates tests based on your flashcard set. Therefore, this mode is excellent to practice before a quiz or exam to assure you have thoroughly learned the words. You can choose different combinations of question types depending on what works best for you.

- Match - This mode lets you race against the clock and match your terms and definitions as quickly as possible. You can use Match mode to compete with your classmates for the top score.

- Gravity - This mode lets you type your answers as the asteroids fall. As you pass levels, the force of gravity increases, and the asteroids start to fall faster for added challenge.

- Live - This mode lets the students work together and enhance communication to find the term that matches the definition. Students stay focused and communicate to win. Everyone on the team must contribute since none of them have all the answers.

Shehane (2015) puts forward several tips for efficiently using Quizlet in language learning classroom. As he clarifies, images are memory hooks. While developing a vocabulary set, one must spice the combination of definitions up with 
images. This is due to the fact that the black and white dictionary definitions are often too abstract and language learners are likely to ignore the definitions and look up for translations. However, with the integration of images and the definitions, language learners may find it satisfying and avoid searching the translations of the words. As it is not feasible to upload more than one image for per vocabulary word on Quizlet, so as to create stronger memory hooks for students, and to assure that images are properly associative, one can take a screen shot of, say, a Google image, crop it, and upload it. Another option is to use GIF (Graphics Interchange Format). Some words, such as fainting or pain, are challenging to explain using only words and a single image. GIFs are dynamic images and are intensely practical for explaining vocabulary efficiently as they isolate an action and show it repeatedly. A 5-second video can communicate the meaning instantly.

\section{Method}

With all its facilitating features, Quizlet seems to be undoubtedly one of the leading applications in vocabulary acquisition. Along with the effectiveness of visualization in acquiring vocabulary, humor, as aforementioned, carries a significant importance in the learning process. Hence, in this study, the visual integration of humor accompanying a vocabulary on Quizlet was taken into scrutiny to see to what extent humor-integrated pictures on Quizlet account for the vocabulary acquisition.

\subsection{Participants}

The learners participating in this study were 45 intermediate EFL learners, ranging from 18 to 27 years old. There were studying at a preparatory school of a private university in Turkey. Their level of proficiency (i.e., intermediate) in English had already been assessed through the standardized placement and proficiency exams of the university respectively. They had been assigned to different classes, two of which were conveniently selected for the purpose of this study. The first group with 22 students was the control group and the other one with 23 was the experimental group of the study.

\subsection{Procedure}

The treatment of the study was mainly based on the assignments on Quizlet. Every week, the both groups received a variety of assignments, i.e., vocabulary sets on Quizlet. The assigned homework of the participants in the first group (control group) was only vocabulary items presented in non-humorous contexts on Quizlet (Figure 1), while the participants in the second group (experimental group) were assigned the identical vocabulary items accompanying humorous pictures or GIFs on Quizlet (Figure 2). The vocabulary items were selected from the reading texts that were studied in the reading course of the semester that lasted for eight weeks. The targeted vocabulary items were the important ones listed at the end of each reading text in the books. During this 8-week treatment, the learners in both groups were assigned homework on Quizlet four times a week with more than ten vocabulary items each time.
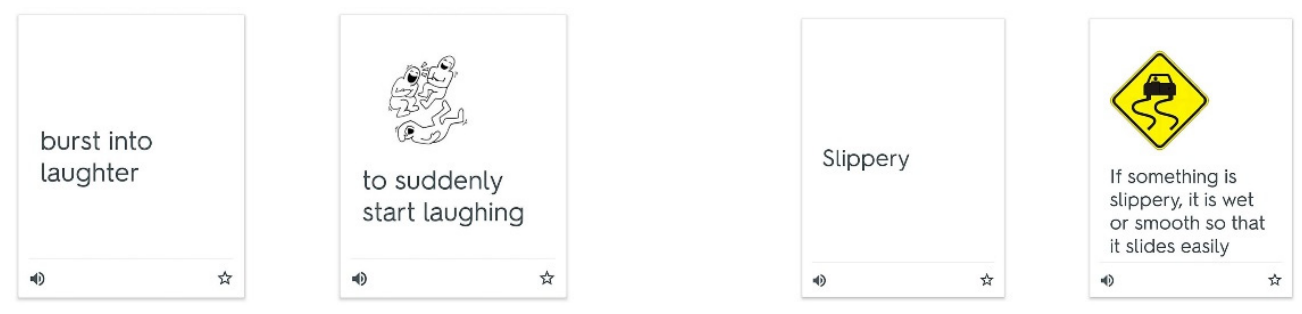

Figure 1. Example of Non-Humorous Vocabulary Flashcard on Quizlet
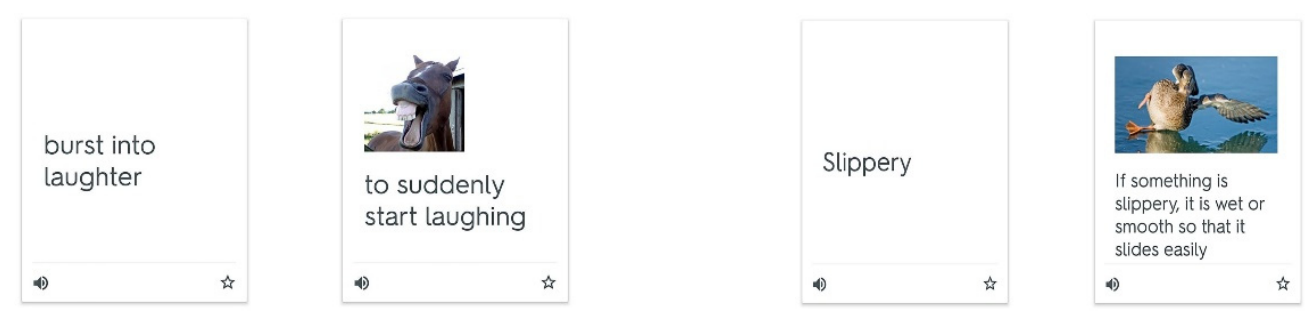

Figure 2. Example of Humorous Vocabulary Flashcard on Quizlet 
Before the treatment starts, there was an instruction session for both groups on how to study the assigned vocabulary items. They were explained that vocabulary acquisition is highly dependent on repeated exposure to target words in context. The popular wisdom accepts that learners need to meet a word 7, 10, or even 20 times. Ten repetition of any unfamiliar vocabulary can lead to learning gains (Webb, 2007). It is not only the number of times that one encounters a word that is important to learning but also the spacing between the repetitions (Zimmerman, 2014). Memory research has indicated that most vocabulary forgetting takes place immediately after the first encounter with new information. This suggests that the first several encounters should be close together, with later encounters spaced apart. So, the learners were asked to study a vocabulary for 3 minutes initially, then for 3 minutes a few hours later, then for 3 minutes the next day, then for 3 minutes 2 days later, and finally a week later, rather than studying a vocabulary for one 15-minute period (Zimmerman, 2014). They were told that fifteen minutes spread across several days at progressive intervals would lead to longer retention than 15 minutes spent all at one time. After giving the instruction to the learners on how to study the assigned vocabulary items, the treatment started. After each assignment, the learners were expected to study the assigned vocabulary items while doing spaced repetition. The learners were asked to practice different game mode activities. That is possible for teacher to track the activities that are done by the members of the online group on Quizlet. So, the teacher in the study checked the assignments every day to monitor the pace of the activities.

\subsection{Instruments}

Before starting the treatment, a pilot study was carried out to test, revise, and finalize the contents of the pretest and the posttest. In order to determine the equivalence of the two tests, two versions of a test were administered to the participants and a correlation coefficient was calculated. The reliability of the test as a whole was calculated as .76, and the unreliable items were excluded.

\section{Results}

At first, the pre-test including 40 multiple choice questions assessing the vocabulary knowledge of the participants was administered. Then, in order to be sure that there was not a significant difference between the pretest score of the control group and that of the experimental group, an independent t-test analysis of variance between the two groups was conducted. The results obtained from the t-test run (Table 1) indicated that there was not a significant difference between the scores of the participants in the control $(\mathrm{M}=56.09, \mathrm{SD}=8.23)$ and the experimental $(\mathrm{M}=56.47, \mathrm{SD}=$ 11.87 ) groups in terms of their vocabulary knowledge $t(43)=-.127, p<.900$.

Table 1. Independent Samples t-test for Pretest

\begin{tabular}{lllllll}
\hline & F & Sig & t & df & $\begin{array}{l}\text { Sig. } \\
\text { (2-tailed) }\end{array}$ & $\begin{array}{l}\text { Mean } \\
\text { Difference }\end{array}$ \\
\hline Equal variances assumed & 3.39 & .072 & -.127 & 43 & .900 & -.38 \\
Equal variances not assumed & & & -.128 & 39.27 & .899 & -.38 \\
\hline
\end{tabular}

Then, to arrive at the purpose of the study, the other equivalent version of the pretest consisting of 40 multiple-choice vocabulary questions was administered as a posttest to the learners. After that, to observe the numerical scores resulting from the posttest followed by the vocabulary assignments accompanying humorous pictures for the experimental group, and the identical vocabulary items with non-humorous pictures for the control group, an independent samples t-test was applied to examine the possible significant difference between them and to observe the intended improvement. The results obtained from the t-test run (Table 2) for the control group and the experimental group showed a significant difference between the scores of the students in the control group ( $\mathrm{M}=$ $72.09, \mathrm{SD}=10.23)$, and that of the experimental group $(\mathrm{M}=90.43, \mathrm{SD}=5.67), t(43)=-7.48, p<.000$

Table 2. Independent Samples t-test for the Posttest

\begin{tabular}{lllllll}
\hline & F & Sig & t & df & $\begin{array}{l}\text { Sig. } \\
\text { (2-tailed) }\end{array}$ & $\begin{array}{l}\text { Mean } \\
\text { Difference }\end{array}$ \\
\hline Equal variances assumed & 5.024 & .030 & -7.48 & 43 & .000 & -18.34 \\
Equal variances not assumed & & & -7.39 & 32.51 & .000 & -18.34 \\
\hline
\end{tabular}




\section{Discussion}

In this study, the effect of integrating humorous pictures using Quizlet on vocabulary learning of EFL learners was taken into scrutiny, and the results indicated that linking vocabulary items with humorous pictures is more effective than using non-humorous context in learning vocabulary. As it is evident, integration of technology in learning vocabulary has been effective in both groups. However, while the mean score of the control group was approximately 73, that of the experimental group was around 91. The findings shed light on the importance of technology in language learning and its linking with humor in vocabulary learning. Apparently, as the results indicate, the significant effectiveness of technology in vocabulary learning can be boosted with the help of humorous context.

Literature review advocate similar effective and constructive role of humor in language learning. Years ago, Kaplan \& Pascoe (1977), for instance, indicated that being exposed to more humorous examples can lead to greater retention of information. In a different study, Schmitt (1994) also found the participants were able to retain the humorous sentences with greater ease than the non-humorous ones. Echoing Kaplan and Pascoe, and Schmitt, Garner (2006) also reported that the humor-integrated group learns and recalls the lectures much better than the other group. The performance of humorous group was also reported to be significantly better than that of non-humorous group (Ghaffari \& Mohamadi, 2012).

Associating the lexical items with a theme or visual aids, as the results of the study indicate, can help to boost vocabulary learning. This idea is also supported by Krashen \& Terrell (2002) who argue in favor of meaningful learning of lexical items. They recommend teaching vocabulary with the help of visual aids and pictures for classroom practice. Echoing Krashen and Terrell, three decades ago Carter \& McCarthy (1988, cited in Ahour, \& Berenji, 2015) similarly indicated that images and other associations enrich the context of vocabulary, which consequently leads to its retainment. Therefore, if the association is within the humorous context, recalling the lexical items can be boosted. Yelbay Yilmaz (2015) similarly believes that associating a lexical item with a mental image makes the item more memorable. In fact, associating the meaning of lexical items with their mental image has been emphasized as it can boost storing of lexical items in long-term memory (Pavicic Takac, 2008). Moeller, Ketsman, \& Masmaliyeva (2009) also underline that visual representations connect the key concept with related events and ideas, which are excellent ways to identify the background knowledge of students, and to organize this knowledge in a way that links what they already know to the new concepts and vocabulary they will be learning. Thornbury (2002) has proposed a list of principles that facilitate memorizing learning materials. These include multiple encounters with a lexical item, preferably at spaced intervals, retrieval and use of lexical items, cognitive depth, affective depth, personalization, imaging, use of mnemonics and conscious attention that seem necessary to remember a lexical item. Directly associating the meaning of a vocabulary item to real objects or phenomena with the help of visual aids is one of the prevalent strategies to present new lexical items to the learners. Visual aids are believed to be helpful in terms of serving as cues for remembering lexical items and result in linguistic and visual storing of information.

\section{Conclusion}

All the studies in line with the findings of this study signify language teachers to pay closer attention to the facilitating role of humor while preparing vocabulary lessons. The prospect of developing vocabulary knowledge through being exposed to the humor-integrated lexical items has a clear practical teaching implication. By inserting humorous and attention-getting pictures rather than insipid and tasteless ones, the langiage teachers can activate the process of vocabulary learning on Quizlet. In fact, with its visual features and the possibility to accompany the visual associations and GIFs with vocabulary items, Quizlet can play a remarkable role in helping vocabulary acquisition. As aforementioned, while developing a vocabulary set, we need to avoid only integrating the black and white dictionary definitions. Instead, inserting a visual aid accompanying the definition in English language is more likely to grab the learners' attention and consequently they may avoid searching for the translation of the words. The chosen image does not have to exactly indicate the meaning of the word, nor does it have to be one shot. They must be greatly associative and serve as a memory hook for learners.

\section{References}

Ahour, T., \& Berenji, S. (2015). A comparative study of rehearsal and loci methods in learning vocabulary in EFL context. Theory and Practice in Language Studies, 5(7), 1451-1457. https://doi.org/10.17507/tpls.0507.18

Aria, C., \& Tracey, D. H. (2003). The use of humor in vocabulary instruction. Reading Horizons, 43, 161-179. 
Basoglu, E. B., \& Akdemir, O. (2010). A comparison of undergraduate students' English vocabulary learning: Using mobile phones and flash cards. The Turkish Online Journal of Educational Technology, 9(3), 1-7.

Bennett, S. J., Maton, K. A., \& Kervin, L. K. (2008). The 'digital natives' debate: a critical review of the evidence. British Journal of Educational Technology, 39(5), 775-786. https://doi.org/10.1111/j.1467-8535.2007.00793.x

Clark, M. (2013). The use of technology to support vocabulary development of English language learners (Master dissertation). Retrieved October 23, 2018 from http://fisherpub.sjfc.edu/education_ETD_masters/238

Deng, Q., \& Trainin, G. (2015). Learning vocabulary with apps: From theory to practice. The Nebraska Educator: A Student-Led Journal, 2, 49-69.

Desberg, P., Henschel, D., \& Marshall, C. (1981). The effect of humor on retention of lecture material. Paper presented at the annual meeting of the American Psychological Association, Montreal, Quebec, Canada. (ERIC Document Reproduction service No. ED223118)

Francis, M. A., \& Simpson, M. L. (2009). Vocabulary development. In R. F. Flippo \& D. C. Caverly (Eds.), Handbook of college reading and study strategy research (pp. 98-117). New York, NY: Taylor \& Francis. https://doi.org/10.4324/9781315629810-9

Frand, J. (2000). The information-age mindset: Changes in students and implications for higher education. EDUCAUSE Review, 35(5), 15-24.

Garner, R. L. (2006). Humor in pedagogy: How huh-huh can lead to aha. College Teaching, 54, 177-180. https://doi.org/10.3200/CTCH.54.1.177-180

Ghaffari, M., \& Mohamadi, R. (2012). The effect of context (humorous vs. non-humorous) on vocabulary acquisition and retention of Iranian EFL learners. International Journal of Applied Linguistics \& English Literature, 1(6), 222-231. https://doi.org/10.7575/ijalel.v.1n.6p.222

Howe, N., \& Strauss, W. (2000). Millennials rising: The next great generation. New York: Vintage.

Kaplan. R. M., \& Pascoe, G. C. (1997). Humorous lectures and humorous examples: Some effects upon comprehension and retention. Journal of Educational Psychology, 69(1), 61-65. https://doi.org/10.1037/0022-0663.69.1.61

Klopfer, E., Squire, K., \& Jenkins, H. (2002). Environmental detectives PDAs as a window into a virtual simulated world. Paper presented at International Workshop on Wireless and Mobile Technologies in Education. https://doi.org/10.1109/wmte.2002.1039227

Krashen, S. D., \& Terrell, T. D. (1995). The natural approach: Language acquisition in the classroom. England: Pearson Education.

Liu, J., \& Zhang, J. (2018). The effects of extensive reading on English vocabulary learning: A meta-analysis. English Language Teaching, 11(6), 1-15. https://doi.org/10.5539/elt.v11n6p1

Moeller, L. A., Ketsman, O., \& Masmaliyeva, L. (2009). The essentials of vocabulary teaching: From theory to practice. Diverse by Design. Central States Conference Report, 1-16. Retrieved May 2, 2018 from https://www.researchgate.net/profile/Aleidine_Moeller/publication/282228232_The_Essentials_of_Vocabulary_ Teaching_From_Theory_to_Practice/links/5911f05d0f7e9b70f48d691e/The-Essentials-of-Vocabulary-Teaching -From-Theory-to-Practice.pdf

Nation, P. (2001). Learning vocabulary in another language. Cambridge; New York: Cambridge University Press. https://doi.org/10.1017/CBO9781139524759

Nie, Y., \& Zhou, L. (2017). A study of vocabulary learning strategies used by excellent English learners. Research on Modern Higher Education, 4, 101-106. https://doi.org/10.24104/rmhe/2017.04.02010

Pavičić Takač, V. (2008). Vocabulary learning strategies and foreign language acquisition. Clevedon-Buffalo-Toronto: Multilingual Matters Ltd. https://doi.org/10.21832/9781847690401

Prenksy, M. (2001). Digital natives, digital immigrants. On the Horizon, 9(5), 1-6. https://doi.org/10.1108/10748120110424816

Rezaei, A., Mai, N., \& Pesaranghader, A. (2014). The effect of mobile applications on English vocabulary acquisition. Jurnal Teknologi, 68(2), 73-83. https://doi.org/10.11113/jt.v68.2912

Schmidt, R. (1994). Deconstructing consciousness in search of useful definitions for applied linguistics. 
Consciousness in Second Language Learning, 11, 237-326.

Shehane, M. J. (2015). Five tips for using Quizlet in the language learning classroom. Retrieved July 4, 2016 from https://www.linkedin.com/pulse/5-tips-using-quizlet-language-learning-classroom-michael -j-shehane/

Taj, I. H., Ali, F., Sipra, M. A., \& Ahmad, W. (2017). Effect of technology enhanced language learning on vocabulary acquisition of EFL learners. International Journal of Applied Linguistics and English Literature, 6(3), 262-272. https://doi.org/10.7575/aiac.ijalel.v.6n.3p.262

Tapscott, D. (1998). Growing up digital: The rise of the net generation. New York: McGraw-Hill.

Thornbury, S. (2002). How to teach vocabulary. Harlow, Essex: Longman.

Wang, B. T., Teng, C. W., \& Chen, H. T. (2015). Using iPad to facilitate English vocabulary learning. International Journal of Information and Education Technology, 5(2), 100-104. https://doi.org/10.7763/ijiet.2015.v5.484

Webb, S. (2007). The effects of repetition on vocabulary knowledge. Applied Linguistics, 28(1), 46-65.

Yelbay Yilmaz, Y. (2015). Learning vocabulary in a foreign language: A computer software based model attempt. Journal of Language and Linguistic Studies, 11(2), 23-38.

Yu, X., \& Altunel, V. (2018). Second language vocabulary learning from context clues: A review of research in the past decade and implementation in digital environment. Journal of Educational Technology \& Online Learning, 1(1), 1-12. https://doi.org/10.31681/jetol.375803

Zhang, H., Song, W., \& Burston, J., (2011). Reexamining the effectiveness of vocabulary learning via mobile. The Turkish Online Journal of Educational Technology, 10(3), 203-214.

Zimmerman, C. B. (2014). Teaching and learning vocabulary for second language learners. In M. Celce-Murcia, D. M. Brinton, \& Snow, M. A. (Eds.), Teaching English as a second or foreign language (4th edition) (p. 288-302). Boston: Heinle Cengage Learning. 